\title{
A Qualitative Research of Cancer Patients' Experience of Participating in Shared Decision-Making
}

\author{
Huei-Lan Chang ${ }^{1}$, Chiou-Fen Lin ${ }^{2, *}$ \\ ${ }^{1}$ Nursing Department, National Taiwan University Hsin-Chu Hospital, Hsin-Chu, Taiwan \\ ${ }^{2}$ College of Nursing, School of Gerontology Health Management, Taipei Medical University, Taipei, Taiwan \\ Email address: \\ jhlg455093014@gmail.com (Huei-Lan Chang), cflin@tmu.edu.tw (Chiou-Fen Lin) \\ *Corresponding author
}

\section{To cite this article:}

Huei-Lan Chang, Chiou-Fen Lin. A Qualitative Research of Cancer Patients' Experience of Participating in Shared Decision-Making. International Journal of Clinical and Experimental Medical Sciences. Vol. 7, No. 4, 2021, pp. 108-114. doi: 10.11648/j.ijcems.20210704.17

Received: June 27, 2021; Accepted: July 20, 2021; Published: July 27, 2021

\begin{abstract}
Cancer is a life-threatening disease, albeit the continued improvement in treatment strategies, there are still many uncertainties during the treatment process and the effectiveness. In the current healthcare settings, shared decision-making (SDM) or patients' preference and values and participation have less frequently been incorporated in the medical decision-making process. SDM has been advocated in Taiwan since 2016. The aim of this study is to investigate patients' experiences of participation in SDM. A qualitative research using in-depth interviews design to present the patient's experience of participating in SDM. Purposive sampling of cancer patients above 20 years old in a teaching hospital in Northern Taiwan from January $15^{\text {th }}$ to April $30^{\text {th }}$ in 2018 was recruited. A total of 25 patients were enrolled for face-to-face in-depth interview, a qualitative content analysis according Graneheim and Lundman. Three themes of experiences and feelings of SDM participation were summarized, i.e., difficulty in making major medical decision, professional support is the most important, and mutual expect in shared decision-making. Six subthemes are shocked by the diagnosis, layman with deficient knowledge of the medical conditions, sufficient information for decision-making, encouragement and support for motivation, one is the master of his own body, and regain confidence to make decisions and face the future. With the development of medical technology, there has been significant improvement in cancer prevention and treatment in recent years. Still, a considerable proportion of cancer patients showed poor response to conventional treatment or control therapies, by which patients prone to face difficulty in choosing treatment options. Shared decision-making is a process of patient autonomy in which patients are equipped with correct understanding of treatment options and are able to make quality decisions.
\end{abstract}

Keywords: Qualitative Research, Cancer Patient, Shared Decision-making, Patient-physician Communication, Experience

\section{Introduction}

Taiwan is the first in Asia to pass the Patient Right to Autonomy Act to protect patient rights in 2016. This act is stipulated to respect patient autonomy, to safeguard their rights to a good death, and to promote a harmonious patient-physician relationship, all of which could possibly be fulfilled via shared decision-making (SDM) [1]. The increase of public willingness to participate in SDM has rendered previous patient education by healthcare professionals insufficient to meet patients' expectations [2].

Shared decision-making (SDM) is defined as an approach for clinicians and patients share to make decisions together with the best available evidence, and patients are supported to consider all options, to achieve informed preferences [3]. The best choice for the patient should be the intersection of best research evidence, clinical experts experience, and patients' value and expectation. Healthcare personnel should take 3Es into consideration, so as to implement SDM based on patients' preferences as well as evidence-based medical recommendations $[4,5]$. Along these lines, patient health literacy, understanding of risks and patient-physician relationship may be improved; whereas decisional conflicts, patients' feeling of being uninformed and inappropriate inspection or treatment may be ameliorated [6]. For patients, autonomy is a right rather than an obligation, and healthcare personnel has to figure out patient's 
willingness to be empowered to choosing the treatment option in line with their values and with most related empirical and safety evidences $[7,8]$.

Currently, it's less common that health care providers make an effort to adjust themselves to patient-centered care and to promote patient participation via SDM $[9,10]$. The Ministry of Health and Welfare (MOHW) has incorporated SDM promotion into national patient safety goals in 2015. Hopefully, patients will be actively participate in the decision-making process and relieve their feelings of being uninformed, thereby the doctor-patient relationship could be improved and the medical quality and patient safety as well.

Qualitative content analysis is an objective and systematic methodology and has been employed by nurse researchers to analyze the conditions of patient participation [11]. In recent years, mixed-methods approach is also widely accepted in nursing research to mutually corroborate and complement the findings in qualitative and quantitative studies [12]. Albeit a lot of manpower, materials, time, and money has been invested in SDM promotion, most SDM studies in Taiwan were focused on the effect and optimization of patient decision aids (PDA), content analysis is still in its infancy and patient experience in SDM remains largely unknown, and it's unclear whether there is any SDM implementation barrier in patient-provider communication. On the other hand, cultural difference in the healthcare environment has prompted us to investigate domestic cancer patient experience in SDM via qualitative analysis.

\section{Methods}

\subsection{Design}

A qualitative research using in-depth interviews design to present the patients' experience of participating in SDM.

\subsection{Participants}

A total of 25 cancer patients were enrolled in the inpatient and outpatient clinics of an 800-bed regional teaching hospital in Northern Taiwan was conducted. The interview lasted 30 to 90 minutes and were digitally recorded. Cancer patients who underwent surgery, medication, treatment, in line with SDM elements, and with full disposing capacity were recruited. Sample size was determined by "theoretical saturation" until adding more participants to the study did not result in additional perspectives or information. The inclusion criteria were conscious clear and able to communicate, aged $>$ 20 years, agree to interview and voice recording, willing and able to give informed consent for participation in this study, and fulfill the SDM requirements (Table 1).

Table 1. Description of the participants.

\begin{tabular}{|c|c|c|c|c|c|c|}
\hline participant & Age (years) & Gender & Educational attainment & Marital status & Occupation & Cancer category \\
\hline $\mathrm{A}$ & 62 & Male & Junior college & Married & Industry & Colorectal cancer \\
\hline B & 46 & Male & Senior high school & Married & Industry & Lung cancer \\
\hline $\mathrm{C}$ & 40 & Male & Senior high school & Single & Industry & Esophageal cancer \\
\hline $\mathrm{D}$ & 73 & Female & Junior high school & Married & None & Thyroid cancer \\
\hline $\mathrm{E}$ & 65 & Male & Senior high school & Married & Retired & Colorectal cancer \\
\hline $\mathrm{F}$ & 51 & Male & Junior high school & Married & None & Esophageal cancer \\
\hline G & 55 & Male & Graduate school & Married & Service industry & Lung cancer \\
\hline I & 62 & Female & Junior high school & Married & None & Colorectal cancer \\
\hline $\mathrm{J}$ & 63 & Female & Senior high school & Married & Service industry & Breast cancer \\
\hline $\mathrm{K}$ & 54 & Female & Junior college & Married & Retired & Lung cancer \\
\hline $\mathrm{L}$ & 52 & Female & Junior college & Married & Industry & Breast cancer \\
\hline M & 57 & Female & Senior high school & Divorced & Homemaker & Breast cancer \\
\hline $\mathrm{N}$ & 65 & Female & Junior college & Married & Retired & Peritoneal cancer \\
\hline $\mathrm{O}$ & 51 & Female & Junior high school & Married & None & Breast cancer \\
\hline $\mathrm{R}$ & 54 & Female & Senior high school & Married & Industry & Breast cancer \\
\hline S & 60 & Female & Elementary school & Married & None & Breast cancer \\
\hline $\mathrm{T}$ & 65 & Male & University & Married & None & Colorectal cancer \\
\hline $\mathrm{U}$ & 64 & Male & Senior high school & Married & None & Colorectal cancer \\
\hline $\mathrm{V}$ & 55 & Female & University & Married & Homemaker & Breast cancer \\
\hline W & 57 & Male & Senior high school & Married & Industry & Lung cancer \\
\hline $\mathrm{X}$ & 54 & Male & Senior high school & Single & None & Lung cancer \\
\hline $\mathrm{Y}$ & 69 & Male & Elementary school & Married & Culture worker & Gastric cancer \\
\hline
\end{tabular}

\subsection{Data Collection}

After referring to the SDM-Q-9 questionnaire and relevant decision-making materials, we formulated interview guidelines. For the consistency in data acquisition, information was collected by the first author has received qualitative research training. Individual interviews were conducted from January $15^{\text {th }}$ to April $30^{\text {th }}, 2018$. A semi-structured in-depth interview, was carried out individually and face-to-face in a quiet single-bedded room or consultation room with use voice recorder pen and cell phone recording. Respondents were 
asked to clarify unclear or omitted answers. The interview came to an end when the information gathered is repetitive and no more new or additional insights were provided. After verbatim transcription, qualitative analysis was carried out to investigate patients' experience of participating in SDM.

\subsection{Data Analysis}

A qualitative content analysis was performed to systematically unveil a deeper understanding in the collected data (Table 2). The authors' was related to their experience as researchers and clinical nurses.

Table 2. Description of the Qualitative Content Analysis According Graneheim and Lundman [13].

\begin{tabular}{ll}
\hline 1 & The audio-recorded data material is transcribed verbatim by the first author, and the transcribed text is further read repeatedly. \\
2 & The basis of classification is the use of inductive analysis to dividing and condense the content and mark it as a meaning unit code. \\
3 & Compare the codes and categorize them into sub-themes, all containing a manifest content. \\
4 & The sub-themes were organized and abstracted into 3 themes by the first and corresponding author. \\
5 & The two authors discussed the meaning of the three themes. More analyses of themes and sub-themes are discovered and integrated in one theme. \\
6 & Compare the data with the sub-themes and discuss the themes verified by reflection with another two qualitative experts.
\end{tabular}

\subsection{Ethical Considerations}

The study was approved by the IRB of National Taiwan University Hospital Hsinchu Branch (106-076-E). This study was conducted in accordance with the Declaration of Helsinki. This study and all participants provided written consent prior to any data collection. The invited patients were informed verbally and in writing about the study and a guarantee of anonymity and confidentiality was given. Confirmation of the fact that participation was voluntary and that the participants could withdraw at any time with no consequences for their further treatment at the hospital was provided prior to the start of the study. The participants are referred to by codename.

\section{Results}

After the analysis of verbatim transcript of the experiences of participation in SDM from 25 patients, three themes were summarized as follows: 3.1 difficulty in making major medical decision, 3.2 professional support is the most important, 3.3 mutual respect in shared decision-making. Major findings on the interview are listed in Table 3.

Table 3. Major findings on the interview.

\begin{tabular}{|c|c|c|c|}
\hline Theme & Definition & Subtheme & Definition \\
\hline \multirow[b]{2}{*}{$\begin{array}{l}3.1 \text { Difficulty in } \\
\text { making major } \\
\text { medical decision }\end{array}$} & \multirow[b]{2}{*}{$\begin{array}{l}\text { It is difficult for the patient to make } \\
\text { decisions in this period }\end{array}$} & 3.1.1 Shocked by the diagnosis & $\begin{array}{l}\text { 3.1.1 The participant was afraid and anxious when the } \\
\text { life-threatening diagnosis is announced. }\end{array}$ \\
\hline & & $\begin{array}{l}\text { 3.1.2 Layman with deficient } \\
\text { knowledge of the medical } \\
\text { conditions }\end{array}$ & $\begin{array}{l}\text { 3.1.2 The participant had no medical and disease-related } \\
\text { knowledge. Since there are multiple treatment options, the } \\
\text { participant preferred listening to the doctor. }\end{array}$ \\
\hline \multirow{2}{*}{$\begin{array}{l}3.2 \text { Professional } \\
\text { support is the } \\
\text { most important }\end{array}$} & \multirow{2}{*}{$\begin{array}{l}\text { The participant was anxious and scared } \\
\text { at a loss due to knowing nothing about } \\
\text { the situation. The medical team } \\
\text { explains the situation and helps the } \\
\text { patient making medical decision. }\end{array}$} & $\begin{array}{l}\text { 3.2.1 Sufficient information for } \\
\text { decision-making }\end{array}$ & $\begin{array}{l}\text { 3.2.1 The physician provides information by various } \\
\text { methods for the patient to understand the disease as well as } \\
\text { pros and cons of all treatment options. }\end{array}$ \\
\hline & & $\begin{array}{l}\text { 3.2.2 Encouragement and support } \\
\text { for motivation. }\end{array}$ & $\begin{array}{l}\text { 3.2.2 The nurse provides consultation and psychological } \\
\text { support, other patients share their experience, all together } \\
\text { reduce the distress and anxiety. }\end{array}$ \\
\hline \multirow{2}{*}{$\begin{array}{l}3.3 \text { Mutual } \\
\text { respect in shared } \\
\text { decision-making. }\end{array}$} & \multirow{2}{*}{$\begin{array}{l}\text { The patients felt respected as the } \\
\text { medical team invites them for the joint } \\
\text { decision-making, and found that they } \\
\text { are capable of making decisions. }\end{array}$} & $\begin{array}{l}3.3 .1 \text { One is the master of his } \\
\text { own body. }\end{array}$ & 3.3.1 Realize that one must make his life-or-death decision. \\
\hline & & $\begin{array}{l}\text { 3.3.2 Regain confidence to make } \\
\text { decisions and face the future. }\end{array}$ & $\begin{array}{l}\text { 3.3.2 Regain self-confidence and establish self-affirmation } \\
\text { after making the decision, face the future with confidence. }\end{array}$ \\
\hline
\end{tabular}

\subsection{Theme: Difficulty in Making Major Medical Decision}

We found in this study that patients were shocked by the announcement of the diagnosis of cancer and refused to accept reality. Therefore, it appears to be difficult for the patient to make decisions under the circumstances.

\subsubsection{Subtheme- Shocked by the Diagnosis}

According to the interview, patients were shocked and disbelieved when the cancer diagnosis was announced. Facing the life-threatening disease, they experienced distress and strong emotions such as fear and helpless, and were worried, panic, depressed, and unacquainted with the decision-making process for the cancer treatment.

A: "How can a patient have his own thoughts when his mind went blank?"

O: "I am nervous and anxious, and I don't think I can make the decision on my own. I will discuss with my family."

P: "I am kind of scared at that time since it was a difficult decision."

$\mathrm{R}$ : "Making this decision is very stressful."

$\mathrm{S}$ : "I was afraid in the first place. I was very nervous and scared when I was diagnosed as cancer. I don't understand why I got this disease at such a young age." 


\subsubsection{Subtheme- Layman with Deficient Knowledge of the Medical Conditions}

In this study, we revealed that in the patients' opinion, they are not medical professionals, so it's difficult for them to make the medical decision. With the rapid development of cancer therapies, there are more and more treatment options available for the patients. In the modern age where information explodes every minute, everyone can access all kinds of information so easily, however, from the cancer patients' perspective, the information from the internet is still not diversified enough, and they are unable to tell the authenticity of the information, which in turn complicates the decision-making process.

A: "The doctor's explanation and recommendation allows me to grasp the central concept of the treatment process."

C: "I'm not familiar with this field and I have limited knowledge of this medical condition."

$\mathrm{H}$ : "I think my medical knowledge is quite limited."

$\mathrm{P}$ : "The doctor discussed with me when there were different treatment options."

\subsection{Theme: Professional Support is the Most Important}

We demonstrated in this study that lack of knowledge led to patients' fear, anxiety, and stress. Explanation and description by the medical team helped relieve the situation and facilitate patients' decision-making process.

\subsubsection{Subtheme- Sufficient Information for Decision-making}

In this study, the physicians provided the patients information in different ways for them to understand the disease as well as pros and cons of all treatment options. Additionally, the medical team provided sufficient and supportive care to have the patient fully informed, help delineate the patients' value and preference, altogether empowered the patients to make decisions satisfying their needs.

A: "My doctor provided all treatment options. The advantages and disadvantages, including the outcome, of each treatment option. He made me understand what I should notice and think about on every step of the treatment procedure."

G: "He started from the development of the disease, so I think he was tailored to my needs. He also asked about my preference for treatment options."

$\mathrm{H}$ : "The doctors answered my questions from top to bottom. They also asked about my concern, and let me choose between subtotal or gross total resection."

$\mathrm{J}$ : "My doctor analyzed my condition very clearly and in detail. He said that I can discuss with my husband before making the decision."

L: "My doctor had a lot of patience when explaining and describing my condition, he really comforted me."

P: "My doctor asked me whether I can accept the side effects of radiotherapy. For my part, this is the right track because patients are fully informed about their condition."

T: "When I faced the difficult choice, the doctor told me some satisfactory options as long as affordable, and he also explained very clear about each cancer stage and corresponding treatment strategies. After that, I made the decision."

\subsubsection{Subtheme - Encouragement and Support for Motivation}

We demonstrated here that in addition to the physicians, other members in the medial team, e.g., nurses, were also very supportive. Based on their profession, they provided patients consultation, mental support, care, and encouragement. Furthermore, we found that sharing of the experiences by other patients suffering from the same disease also projected positive energy to our patients.

B: "From my point of view, the nurses helped me the most."

C: "Nurses and psychologists came to see me and gave me some good advice during this period. I think the nurse practitioner helped me a lot because he always came to understand my hesitation and needs."

M: "Nurses, psychologists, nutritionists all explained my illness to me. They are experts in different disciplines, and their advices and care from different perspectives really helped a lot."

P: "Nurses, nutritionists, and physical therapists all came to see my movements. They all explained in detail, and it's hard for me to say who helped the most."

\subsection{Theme: Mutual Respect in Shared Decision-making}

Here we revealed patient autonomy that the participants identified themselves as the master of their own body and it's logical to decide the treatment scheme by themselves. They also appreciated and agreed with the medical team on the shared decision-making strategy.

\subsubsection{Subtheme- One Is the Master of His Own Body}

After the consultation and explanations, the patient deeply recognized that it's his own life and he should master his treatment strategy.

F: "This is my own body, and I should take control of my health care. No one can make the decision for me."

$\mathrm{K}$ : "After the detailed explanation by the doctor, I made a quick decision."

$\mathrm{R}$ : "He gave me time for me to think about it, which is good because this is my own body and I supposed to make my own decision."

$\mathrm{T}$ : "As for me, this is a consensus mainly based on my judgment."

\subsubsection{Subtheme- Regain Confidence to Make Decisions and Face the Future}

Based on this study, albeit shocked by the severe illness, cancer patients were capable of making medical decision after joining the medical team to improve their medical knowledge specific for the disease condition. The patients also appreciated the medical team letting them regain self-confidence and face the future with courage.

F: "An empathetic understanding will earn our trust and 
allow us to think over the treatment options."

G: "There is a smooth communication between the doctor and me, and the prognosis is just the same as I anticipated."

J: "I fully accept and am very satisfied with this treatment strategy. Don't be afraid, be brave."

$\mathrm{K}$ : "My tumor is removed now, felling like a weight has been lifted off my shoulder."

M: "In the tense healthcare climate, such communication empowered us to choose and confirm our favorite treatment strategy. So for me, it's quite important to speak your mind."

$\mathrm{N}$ : "Don't be afraid of asking questions. The more $Q$ and $A$, the easier you and your doctor will reach consensus. This experience of communication is completely different from what I previously encountered."

$\mathrm{X}$ : "I like the way he communicated with me, this helped me make the decision. I am glad about this result."

Y: "This is really a smooth progression and we reached the consensus eventually. I have no regrets about my decision."

\section{Discussion}

In the current study, most participants experienced the emotional distress, i.e., in the "Difficulty in making major medical decision" theme, patients described "Shocked by the diagnosis" and "Layman with deficient knowledge of the medical conditions". Our finding is consistent with both domestic and foreign studies that as the disease progresses, up to $45 \%$ of cancer patients experience significant emotional distress. All cancer patients suffer from varying degrees of anxiety and depression $[14,15]$. In a study of breast cancer patients assessed 3 to 5 years after initial diagnosis, approximately $40 \%$ of the participants had anxiety, and $25 \%$ suffered from depression [16]. In another study of cancer patients with 55 years old in average, about $55 \%$ indicated a depressed mood, and 46\% suffered from anxiety [17]. Most estimation of cancer prognosis is the prediction of survival rate after diagnosis, which rendered cancer patients more anxious about decision-making. On the other hand, the emotional distress may also resulted from the information asymmetry between physicians and patients that patients are unfamiliar with medical treatment, and traditionally, medical decision-making is usually dominated by medical personnel and the patients are passive recipient of care [18]. Legare et al. [9] revealed that $54 \%$ patients were unable to determine whether they were choosing the correct option during the decision-making process. When the decision-maker is not equipped with enough knowledge and clear value or belief, the resulting stress may lead to physical and mental health problems such as accelerated heartbeat, persistent muscle tension, irritability, sleeping problems and mental strain [19]. With the expanded access to medical information, patient autonomy and respecting patient's choice are promoted at home and abroad [20]. Furthermore, clinical practitioners or agents are always less comfortable with medical decision-making without patient's thoughts involved [21].

In the second theme, i.e., "Professional support is the most important", the participants highly recognized "enough information for decision-making" and "encouragement and support for motivation" provided by the medical team, which is largely the same as the studies at home and abroad. The value of medical decision-making is the "fusion" of horizons, which in turn leads to the final decision, i.e., medical practitioners shall try to expand their horizons to reach the patient's viewpoint, and then down-to-earth medical recommendations for the patients can be precipitated. For the patients, they shall think about how to make people understand their struggle, such that they can get more help. Only the fusion of horizons of the both parties creates the value of shared decision-making [22]. A study in Jefferson Medical College on 891 patients showed the positive effect of physicians' empathy on patient-physician relationship [23] Practicing "showing respect to others" [24]. True value of medical service is more than "cure", but "healing". Healing is not only how to diagnose and treat the "disease", but to show empathy for "patient's" suffering, to understand their real situation, and to be with the patients in line with their need. It's important to practice what you preach, actions based on sympathy and understanding are the true implementation of empathy, and are really powerful [22]. The establishment of good patient-physician relationship and implementation of empathy must base on sympathy, understanding and practice. This is how the medical staff can truly recognize patients' thinking and choices, and the patients can fully understand what medical professionals convey. The goal of shared decision-making can be achieved only by transforming the understanding to real empathetic actions, this highly dynamic interaction requires active engagement of the patient and clinician, and will result in a positive impact on both parties [22].

Finally, in the theme of "mutual respect in shared decision-making", participants expressed "one is the master of his own body", and "regain confidence to make decisions and face the future" via SDM. Our result echoes foreign studies that the best choice is made only when there is enough time for leaning and evaluation [25]. Uncertainty is a central determinant in decisional conflict. The factors contribute to uncertainty include feeling uninformed or unclear value and beliefs, feeling unclear about personal values for benefits and risks/side effects, feeling unsupported in decision-making, and feeling uncertain about the best choice or regarding ineffective of overall options [26, 27]. Hickman, Daly, and Lee [28] reported uncertainty may arise from insufficient information, lack of psychological support, social pressures, limited time, and unclear explanations from healthcare professionals. Previous studies have summarized managements of decisional conflicts, including 1) providing medical information and resources for expected concerns of care, such as counselors and health education manuals. Appropriate audio or visual recordings during consultation for the decision-makers to have complete and correct information, and the counselors can help clarify the decision-maker's hesitations at the first moment; 2) providing proper emotional support, such as regular phone interviews for decision-maker to release internal and external 
stress during the decision-making process, such that they are able to make the choice best fit their need. On top of the correct understanding of treatment options and the strategies mentioned above, decision makers are able to improve the knowledge and communication skills for both patients and clinicians, and utilize the resources effectively, so as to eliminate the decisional conflicts [29-31].

This study was only conducted in a hospital in northern Taiwan, and it is difficult to infer the experience and feelings of cancer participating shared decision-making in all regions. I hope that there will be opportunities to expand the area of implementation in the future.

\section{Conclusion}

In this study of interaction with cancer patients, we demonstrated the most common problem in decision-making, the patients' hesitation to make the decision because they believed they are laymen to medical profession. It frustrated and threatens the patients' confidence in making choices. Being at a loss, patients gradually adopted the clinicians' decision and neglected their own preference and values. Nevertheless, the promotion of shared decision-making allows the conversation between physician, i.e., the medical expert, and patient, i.e., the expert of his own body, their teamwork to come to the best treatment option for both patient and medical care, elimination of tense patient-physician relationship and medical information asymmetry, establishment of two-way communication and mutual trust between clinicians and patients, as well as creating patient-centered team-based primary care, eventually to improve patient autonomy and increase patient confidence and being respected in healthcare decisions.

Patient autonomy with healthcare decisions is highly related to their health literacy. We demonstrate patients' willingness to make decision for the treatment of their own illness. Therefore, in addition to the development of patient decision aids (PDA), it's critical for medical staff to provide health literacy materials for patients to understand what the healthcare personnel would like to convey, and then be capable of making the choice fitting in with their needs. What's equally important is the training of clinical coach. Nurse practitioners are the staff having the closest and longest interaction with the patients. On top of professional knowledge of medical care, nurse practitioners act as educators and consultants for the patients, and therefore are important clinical coach candidates for people making healthcare decisions.

\section{Acknowledgements}

We appreciate Professor Meixiu Lu, Professor Xuanyi Huang, Professor Shuyuan Liang and Associate Professor Meilan Ke for their guidance and recommendations in the research process. We are even more grateful to all patient with cancers who participated in this study.

\section{References}

[1] Lu, M. S. Medical and Nursing Ethics. Taipei: Wu Nan; 2018.

[2] Ministry of Health and Welfare: Taiwan Patient Safety Net questionnaire Survey of 2015. Available from: http://www.patientsafety.

mohw.gov.tw/Content/Messagess/list.aspx?SiteID=1\&MmmI $\mathrm{D}=621273300443065506$. Accessed October 11, 2019.

[3] Elwyn G, Laitner S, Coulter A, Walker E, Watson P, Thomson R. Implementing shared decision making in the NHS. BMJ. 2010; 341: c5146. doi: 10.1136/bmj.c5146.

[4] Wang, Y. Y. (2016) Shared decision-making: Patient decision aids and the Clinical application. Journal of Healthcare Quality. 10 (4), 15-24.

[5] Tamirisa, N. P., Goodwin, J. S., Kandalam, A., Linder, S. K., Weller, S., Turrubiate, S.,... \& Riall, T. S. (2017). Patient and physician views of shared decision Making in cancer. Health Expectations, 20 (6), 1248-1253.

[6] Davey, H. M., Davey, E., Houssami, N., Barratt, A., Redman, S., Butow, P. N., \& Salkeld, G. P. (2002). Medical tests. Health Expectations, 5 (4), 330-340.

[7] Charles, C., Gafni, A., \& Whelan, T. (1997). Shared decision-making in the medical encounter: what does it mean? (or it takes at least two to tango). Social science \& medicine, 44 (5), 681-692.

[8] Ballesteros, J., Moral, E., Brieva, L., Ruiz-Beato, E., Prefasi, D., \& Maurino, J. (2017). Psychometric properties of the SDM-Q-9 questionnaire for shared decision-making in multiple sclerosis: item response theory modelling and confirmatory factor analysis. Health and quality of life outcomes, 15 (1), 1-6.

[9] Légaré, F., Kearing, S., Clay, K., Gagnon, S., D’Amours, D., Rousseau, M., \& O'Connor, A. (2010). Are you SURE?: Assessing patient decisional conflict with a 4-item screening test. Canadian family physician, 56 (8), e308-e314.

[10] Couët, N., Desroches, S., Robitaille, H., Vaillancourt, H., Leblanc, A., Turcotte, S.,... \& Légaré, F. (2015). Assessments of the extent to which health-care providers involve patients in decision making: a systematic review of studies using the OPTION instrument. Health Expectations, 18 (4), 542-561.

[11] Currey, J., Browne, J., \& Botti, M. (2006). Haemodynamic instability after cardiac surgery: nurses' perceptions of clinical decision-making. Journal of clinical nursing, 15 (9), 1081-1090.

[12] Liang, S. Y., Chuang, Y. H., and Wu, S. F. (2012) Preliminary application of content analysis to qualitative nursing data. The journal of Nursing. 59 (5), 84-90.

[13] Graneheim, U. H., \& Lundman, B. (2004). Qualitative content analysis in nursing research: concepts, procedures and measures to achieve trustworthiness. Nurse education today, 24 (2), 105-112.

[14] Carlson, L. E., \& Bultz, B. D. (2003). Cancer distress screening: needs, models, and methods. Journal of psychosomatic research, 55 (5), 403-409. 
[15] Mukherjee, A., Mazumder, K., Kaushal, V., \& Ghoshal, S. (2017). Effect of supportive psychotherapy on mental health status and quality of life of female cancer patients receiving chemotherapy for recurrent disease. Indian journal of palliative care, 23 (4), 399.

[16] Akel, R., El Darsa, H., Anouti, B., Mukherji, D., Temraz, S., Raslan, R.,... \& Assi, H. (2017). Anxiety, depression and quality of life in breast cancer patients in the levant. Asian Pacific journal of cancer prevention: APJCP, 18 (10), 2809.

[17] Fradelos, E. C., Papathanasiou, I. V., Veneti, A., Daglas, A., Christodoulou, E., Zyga, S., \& Kourakos, M. (2017). Psychological Distress and Resilience in Women Diagnosed with Breast Cancer in Greece. Asian Pacific Journal of Cancer Prevention, 18 (9), 2545-2550.

[18] Yang, J. Y., Chung, H. C., Chou, S. Y., Yeh, T. F., and Chen, C. L. (2018) Effect of shared decision-making of patient anxiety and treatment choice. Cheng Ching Medical Journal. 15 (3), 16-23.

[19] Parayre, A. F., Labrecque, M., Rousseau, M., Turcotte, S., \& Legare, F. (2014). Validation of SURE, a four-item clinical checklist for detecting decisional conflict in patients. Medical Decision Making, 34 (1), 54-62.

[20] Koedoot, N., Molenaar, S., Oosterveld, P., Bakker, P., de Graeff, A., Nooy, M \& de Haes, H. (2001). The decisional conflict scale: further validation in two samples of Dutch oncology patients. Patient education and counseling, 45 (3), 187-193.

[21] Lu, P. P., Chen, M. L., Chung, C. H., Tang, W. R. (2004). The Recognition and Attitude of Cancer Patients and their Families on Do-not-resuscitate. The Journal of Oncology Nursing, 4 (1), $15-22$.

[22] Huang, L. L. (2018). From Sympathy to Empathy-Is It Possible to Have a Good Physician-Patient Communication without" Fusion of Horizons"? UNIVERSITAS-MONTHLY REVIEW OF PHILOSOPHY AND CULTURE, 45 (8), 163-179.

[23] Hojat, M., Louis, D. Z., Markham, F. W., Wender, R.,
Rabinowitz, C., \& Gonnella, J. S. (2011). Physicians' empathy and clinical outcomes for diabetic patients. Academic Medicine, 86 (3), 359-364.

[24] Huang, L. L., Wu, Y. J. "'Empathy Triad' to Enhance 'Genuine' Shared Decision-making". October 2017. Taiwan Association of Medical Education symposium.

[25] De Heredia, R. A. S., Arocena, F. L., \& Gárate, J. V. (2004). Decision-making patterns, conflict sytles, and self-esteem. Psicothema, 110-116.

[26] Légaré, F., Turcotte, S., Stacey, D., Ratté, S., Kryworuchko, J., \& Graham, I. D. (2012). Patients' perceptions of sharing in decisions. The Patient-Patient-Centered Outcomes Research, 5 (1), 1-19.

[27] Turcotte, J., York, C., Irving, J., Scholl, R. M., \& Pingree, R. J. (2015). News recommendations from social media opinion leaders: Effects on media trust and information seeking. Journal of Computer-Mediated Communication, 20 (5), $520-535$.

[28] Hickman Jr, R. L., Daly, B. J., \& Lee, E. (2012). Decisional conflict and regret: consequences of surrogate decision making for the chronically critically ill. Applied Nursing Research, 25 (4), 271-275.

[29] Mishel, M. H., Germino, B. B., Lin, L., Pruthi, R. S., Wallen, E. M., Crandell, J., \& Blyler, D. (2009). Managing uncertainty about treatment decision making in early stage prostate cancer: a randomized clinical trial. Patient education and counseling, 77 (3), 349-359.

[30] Fagerlin, A., Zikmund-Fisher, B. J., \& Ubel, P. A. (2011). Helping patients decide: ten steps to better risk communication. Journal of the National Cancer Institute, 103 (19), 1436-1443.

[31] Hacking, B., Wallace, L., Scott, S., Kosmala-Anderson, J., Belkora, J., \& McNeill, A. (2013). Testing the feasibility, acceptability and effectiveness of a 'decision navigation' intervention for early stage prostate cancer patients in Scotland - A randomized controlled trial. Psycho-Oncology, 22 (5), 1017-1024. 